\title{
DNA-Based Applications in Nanobiotechnology
}

\author{
Khalid M. Abu-Salah, Anees A. Ansari, and Salman A. Alrokayan \\ King Abdullah Institute for Nanotechnology and Centre of Excellence in Biotechnology, King Saud University, \\ P.O. Box 2454, Riyadh 11451, Saudi Arabia
}

Correspondence should be addressed to Khalid M. Abu-Salah, abusalah@ksu.edu.sa

Received 20 August 2009; Revised 4 March 2010; Accepted 18 April 2010

Academic Editor: John B. Vincent

Copyright $\odot 2010$ Khalid M. Abu-Salah et al. This is an open access article distributed under the Creative Commons Attribution License, which permits unrestricted use, distribution, and reproduction in any medium, provided the original work is properly cited.

\begin{abstract}
Biological molecules such as deoxyribonucleic acid (DNA) have shown great potential in fabrication and construction of nanostructures and devices. The very properties that make DNA so effective as genetic material also make it a very suitable molecule for programmed self-assembly. The use of DNA to assemble metals or semiconducting particles has been extended to construct metallic nanowires and functionalized nanotubes. This paper highlights some important aspects of conjugating the unique physical properties of dots or wires with the remarkable recognition capabilities of DNA which could lead to miniaturizing biological electronics and optical devices, including biosensors and probes. Attempts to use DNA-based nanocarriers for gene delivery are discussed. In addition, the ecological advantages and risks of nanotechnology including DNA-based nanobiotechnology are evaluated.
\end{abstract}

\section{Introduction}

Nanoscience and nanotechnology are defined differently depending upon the scope and context of each application. The Royal Society of the UK makes the distinction between nanoscience and nanotechnology where the former includes the "study and manipulation" of nanoscale particles and systems, and the latter the "design, characterization, and production of structures, devices and systems" at the nanoscale $\left(1 \mathrm{~nm}=10^{-9}\right.$ meters, or one billionth of a meter). Nanoscience and nanotechnology involve research and technology development at the atomic, molecular, or macromolecular level, in the length scale of approximately 1 to $100 \mathrm{~nm}$ range. This may lead to the concept of renaming nanosized objects of biology and chemistry (molecules) as tiny machines [1]. For instance, ATP synthase which catalyses the synthesis of adenosine triphosphate (ATP) molecule, which is the universal currency of free energy in living systems, can be called a "nanomotor," so are the enzymes which catalyze making, breaking, and rearranging the bonds in other molecules. Another example is the actinmyosin molecular machine which can drive fibers past one another. Similarly DNA serves as a data storage system, transmitting digital instructions to molecular machines, the ribosomes, that manufacture protein and enzyme molecules in turn, make up most of the molecular machineries in living systems.

Nanobiotechnology employs nanoscale principles and techniques to understand and transform biosystems (living or non-living) and uses biological principles and materials to create new devices and systems integrated from the nanoscale. The integration of nanotechnology with biotechnology as well as with cognitive science and infotechnology is expected to expand exponentially in the next few years [2]. The goal of this article is to highlight recent advances in DNA-based organizations and their applications in nanobiotechnology.

\section{Approaches to Nano Design}

A literature survey on creating structures at nanoscale indicates that a variety of methods having been devised to achieve this goal. These methods can be summarized as the top-down and the bottom-up approaches.

2.1. Top-Down Approach. The top down approach uses natural and man-made chunks or blocks that are cast, sawed or machined into precisely formed products, small 
or large, ranging from integrated circuits to jumbo jets. Methods to produce nanoparticles from bulk materials include high energy ball milling, solution based chemistry, mechano-chemical processing, etching, electro explosion, sonication and physical and chemical vapor deposition techniques. Patterned structures which are grown by suitable lithographic and ion implantation techniques are the cornerstone of silicon integrated chip technology. Nevertheless, conventional technologies such as the photolithographic method are difficult to continue to scale down due to real physical limitations including size of atoms, wave length of radiation used for lithography and interconnect schemes. It is thus clear that an alternative approach based on possibly completely different principles such as the bottomup approach would be required to overcome this barrier toward miniaturization.

2.2. Bottom-Up Approach. Bottom-up approach is the manufacturing of nanomaterials by manipulating and organizing individual atoms and molecules into particular configurations in a fashion similar to processes performed by molecular machines in living organisms. The self-assembly lipid molecules into nanostructure such as liposomes [3-7] can be considered as a classical example on the bottom-up approach for constructing nanomaterials. Another impressive example of atom by atom growth of nanostructures is the writing of the IBM logo by placing individual atoms on a surface using an STM tip [8]. The key to the application of nanotechnology will be the development of processes that control placement of individual atoms to form products of great complexity at extremely small scale [9]. The advantage of bottom-up approach would be a nearly infinite flexibility to create any substance, object, device, machine or material through atom (or molecule) by atom (or molecule) construction. It is natural to expect that the encounters of top-down and bottom-up design systems at nanoscale will result in innovative productivity that will mark a new era.

\section{New Properties and Characteristics of Nanoparticles, Structures and Systems}

The boundaries between the physical regions of macroscopic, microscopic, and nanoscopic are not well defined and they depend on the effects being considered [10]. Nevertheless, materials of the macro-scale usually exhibit similar physical properties to those of the bulk form. On the other hand, reducing the grain size of a material below certain limits results in the appearance of either new or changed chemical and/or physical properties of the material and hence has a dramatic impact on structural, thermodynamic, electronic, spectroscopic, electromagnetic and chemical properties [11]. This may be attributed to either one or more of the following factors

(i) Inherent crystalline grains approaching the size of the characteristic physical length of the relevant properties (ii) An increase in the proportion of the interstitial defects and their impact on dependent properties; and

(iii) The appearance of new structural and/or functional properties that characterize the grain boundaries of the material [12].

One of the most important aspects of nanotechnology is the preparation and development of nanoparticles [13, 14]. A variety of techniques have been reported for preparing different types of nanoparticles [15-17]. The nanoparticles can be made with different materials such as carbon, gold [18], silver [19], and silicon [20] and as small as $1 \mathrm{~nm}$ [1323].

It has been observed for example, that the electrical conductivity of carbon in the form of "nanotubes" is much higher than carbon in the form of diamonds, due to it having a different structure at the nanoscale level. Similarly, gold reflects red light in its tiny nanoparticles form. The fact that gold reflects red light at the nanoscale is exploited in the design of experimental systems that kill cancerous cells with normal visible light, but leave normal cells unharmed $[24,25]$. Moreover, gold becomes a highly efficient catalyst as the transition to nanoscale is introduced. Silver nanoparticles on the other hand, exhibit bioactive properties that are not found in larger particles [26]. These new properties might be exploited for novel applications and this is at the heart of much of the enthusiasm about nanotechnology.

The miniaturizing of bulk silicon creates silicon nanoparticles the fullerene-like structure of which is $\mathrm{Si}_{29} \mathrm{H}_{24}$ [27]. Nanoparticles have properties both electronic and nonelectronic which are not available in bulk nonminiaturazied silicon. These include ultra bright luminescence such that emission from single particles is readily detectable $[28,29]$ stimulated emission [30], collimated emission beams [31] and second harmonic generation [32] from films of the particles. Most importantly the particles are photo-stable and do not blink. The exceptional optical properties, ultra small size, low cost and photostability provide the ultimate sensitivity and special resolution imaging capabilities.

\section{DNA Structure and Function}

Biological molecules such as deoxyribonucleic acid (DNA) have shown great potential in fabrication and construction of nanostructures and devices. It is the basic building block of life. DNA is the genetic material of most organisms and organelles, although phage and viral genomes may use single stranded DNA, single stranded RNA (ribonucleic acid) or double stranded RNA [33]. Most hereditary information is encoded in the chemical language of DNA and reproduced in most cells of living organisms. The double stranded helical structure of DNA is a key to its use in self assembly applications. Each strand of the DNA is about $2 \mathrm{~nm}$ wide. Each helix or strand of DNA is made up from three components: nitrogen-containing bases, carbohydrate (deoxyribose) and phosphate. There are 4 types of nitrogen-containing base in DNA. They are adenine, guanine, cytosine and thymine. The sugar deoxyribose, forms, with phosphate groups, 
a very long backbone, alternating sugar-phosphate-sugarphosphate, and so on. One of the 4 nitrogen containing bases is linked to every sugar molecule. Each unit of a phosphate, a sugar molecule and base is called a nucleotide and is about $0.34 \mathrm{~nm}$ long, that is, 10-10.6 nucleotide pairs for a pitch of 3.4-3.6 nm [34]. Thus, constructions made from DNA will have nanoscale features. The specific binding through 3 hydrogen bonds between cytosine $(\mathrm{C})$ and guanine $(\mathrm{G})$ and 2 such bonds between adenine $(\mathrm{A})$ and thymine $(\mathrm{T})$ can result in the joining of two complementary single stranded DNA to form a double stranded DNA. The phosphate ion carries a negative charge in the DNA molecule, which results in electrostatic repulsion of the two strands [35]. To keep the negative charges neutralized, positive ions must be provided by the solution. The joining of two complementary single strands of DNA through hydrogen bonding to form a double stranded DNA is called hybridization. If a double stranded DNA is heated above certain temperature, the two stands will start to dehybridize and eventually separate into single strands. As the temperature is reduced, the two strands will eventually come together and rehybridize to form the double stranded structure. DNA has several advantages to be used for the assembly of devices and computational elements, for the assembly of interconnects or as the device element itself. First, DNA is the molecule whose intermolecular interactions are the most readily programmed and reliably predicted where $G$ pairs with $C$ and A pairs with T. Thus, the very properties that make DNA so effective as genetic material also make it a very suitable molecule for programmed selfassembly. Second, DNA of a variety of sequences can be obtained by convenient solid support synthesis. Besides, DNA modifications with biotin groups and fluorescent labels introduced new applications for DNA in nanobiotechnology. Third, DNA can be modified by a large group of enzymes that include restriction endonucleases, exonucleases, and DNA ligases.

\section{DNA-Based Nanostructure Assembly}

DNA is a promising candidate to serve as a construction material in nanotechnology. The highly specific WatsonCrick hydrogen bonding allows convenient programming of artificial DNA receptor moieties. The power of DNA as a molecular tool lies in the high mechanical rigidity of short double helixes which allows them to behave effectively like a rigid rod spacer between two tethered functional molecular components on both sides. Moreover, DNA displays a relatively high physicochemical stability.

The use of DNA for the fabrication of nanostructures is rapidly expanding in three main different directions.

(i) The fabrication of artificial networks consisting of native DNA.

(ii) The attachment or integration of DNA onto solid state surfaces.

(iii) The formation of metal or semiconductor nanoparticle assemblies along DNA.
The missing element to make natural DNA the bases for interesting nanomaterials is a point where the helix axis can branch. Such DNA branch points occur as ephemeral structures in cellular DNA metabolism, including replication and repair. They are prominent in the Holliday structure [36], a four-arm branched intermediate in the process of genetic recombination. It is feasible to design sequences of DNA molecules that lead to stable synthetic variants of Holliday junctions, branched molecules with varied numbers [37], as well as more complex motifs. Figure 1, for example, shows a four-armed stable branched DNA junction made by DNA molecules and the formation of a two-dimensional lattice from a four-arm junction with sticky ends [38]. The use of branched intermediates allows us to make connected structures from DNA $[39,40]$, as well as periodic $[41,42]$, and aperiodic arrays [43-45].

Another approach utilizes rigid tetrahedral organic vertices, where the attached oligonucleotides serve as the connectors for the design of more complex architectures. Thus a variable number of oligonucleotide arms could be attached to the core tetrahedral organic linkers, thereby allowing for the construction of different types of DNA structure [46]. One way to exploit this extraordinary precise architectural control is to use self assembled DNA templates to position functional molecules: examples include nanomechanical devices [47-49], molecular electronic circuits [50, 51], near field optical devices [52] and enzyme networks [53]. The simplest active DNA nanostructures are switches that can be driven between two conformations. Motion is induced by changes in ionic conditions, temperature or by the binding of signaling molecule, often a DNA strand [54].

\section{Attachment or Integration of DNA onto Surfaces}

Attachment of biomolecules such as DNA onto the nanomaterials surface plays a crucial role in the choice of immobilization technique suitable for construction of nanodevices such as bio-electronic devices. Long term use, fast response, operational stability and reproducibility of the electrochemical biorecognition event, are some general aspects for employing the immobilization strategy [55]. Selection of the most appropriate immobilization protocol is strictly dependent on the characteristics of the transducing nanomaterial, robust immobilization chemistries are usually preferred in order to prevent desorption of the probes from the sensing layer.

The first step toward DNA-based technology is to attach DNA molecules to surfaces. Three different methods for such an attachment are used.

(i) Electrostatic interaction between DNA and a substrate.

(ii) Covalent binding of a chemical group attached to the DNA end.

(iii) Binding of a protein attached to the DNA end to the corresponding antibody immobilized at the surface. 


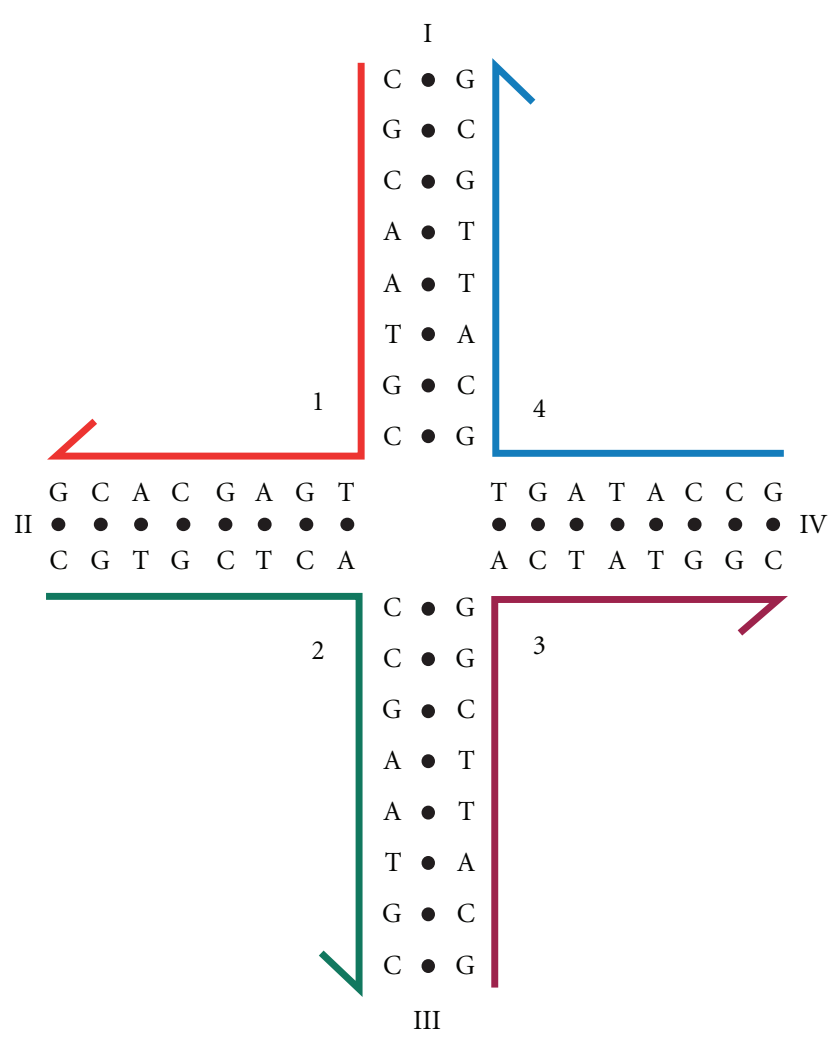

(a)
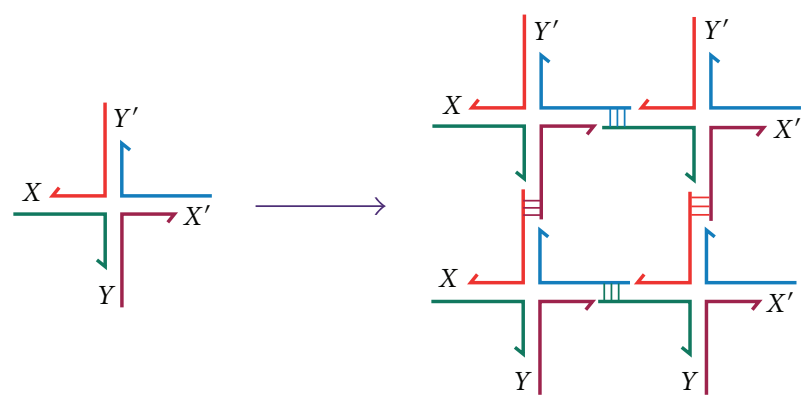

(b)

Figure 1: (a) Sequence of an immobile 4-armed DNA junction. (b) Formation of two dimensional lattice from a four-arm junction with sticky ends, $X$ and $Y$ are sticky ends, $X^{\prime}$ and $Y^{\prime}$ are their sticky ends, respectively. Courtesy of Nadrian C. Seeman.

So far the most widely used method utilizes the covalent bond between sulfur and gold. For example, the DNA molecule can be functionalized with a thiol $(\mathrm{S}-\mathrm{H})$ or disulfide (S-S) group at the $3^{\prime}$ or $5^{\prime}$ end [56-58]. Hwang et al. [59] demonstrated chemical attachment of thiol-terminated DNA molecules at the surface of an Au nanoparticle (see Section 9).

Due to enhanced surface volume or surface area and high surface free energy of nanoparticles can adsorb biomolecules strongly and play an important role in the attachment of biomolecules in the construction of biosensors [11, 55]. Generally, the adsorption of biomolecules directly onto naked surfaces of bulk materials may frequently result in their denaturation and loss of bioactivity. However, the adsorption of such biomolecules onto the surfaces of nanoparticles can retain their bioactivity, because small nanomaterials have ability to reduce the distance between the redox site of immobilized protein or DNA and the working electrode surface which composed of indium-tin-oxide, gold, platinum, glassy carbon, carbon paste, and so forth, since the rate of electron transfer is inversely dependent on the exponential distance between them. Since most of the nanoparticles carry charges, they can electrostatically adsorb biomolecules with different charges (Figure 2). Besides the common electrostatic interaction, other strategies to attach DNA to surfaces include covalent binding of DNA oligonucleotide to a preactivated surface [60] and adsorption of biotinylated oligonucleotide on a particle surface coated with avidin [61-63].

Ansari et al. immobilized probe DNA onto sol-gel derived nanostructured $\mathrm{ZnO}$ matrix for the hybridization detection of target sexually transmitted disease and investigated the bioactivity of the probe DNA electrode [64]. Many similar studies on other nanoparticles such as $\mathrm{Au}, \mathrm{Ag}$, $\mathrm{Pt}, \mathrm{CeO}_{2}, \mathrm{TiO}_{2}, \mathrm{ZrO}_{2}$ have been reported in the literature for the construction of DNA based biosensors for the immobilization of different probe DNA for different disease markers [11,65].

\section{DNA-Based Organization of Metal Nanoparticles}

There has been a tremendous interest in recent years to develop concepts and approaches for self assembled systems. The use of DNA to assemble metals or semiconducting nanoparticles can be achieved mainly by three different approaches.

(i) The electrostatic binding of positively charged colloids to the negatively charged DNA.

(ii) The specific binding of colloids to DNA via chemical bonds. Either DNA and / or colloids can be modified with functional groups, such as thiol groups, or with biotin-streptavidin complexes. Also colloids carrying oligonucleotides can be hybridized with single stranded parts of DNA.

(iii) The direct growth of nanoparticles along the DNA molecules. This can be accomplished by the formation of nucleation sites along DNA molecules followed by metal or semiconductor deposition by chemical reduction of the corresponding salt.

Several studies have been conducted [56] aiming at assembling colloidal gold nanoparticles into macroscopic aggregates using DNA as linking elements. One such study was published by Kumar and co-worker who managed to cross-link sulphur substituted DNA with gold nanoparticles in solution using phosphothioate DNA as a structural interconnect [57]. Another approach was reported by Alivisatos et al. [61] who managed to organize gold nanocrystals into specially defined structures. Their approach involved the attachment of gold to either $3^{\prime}$ or the $5^{\prime}$ end of 19 


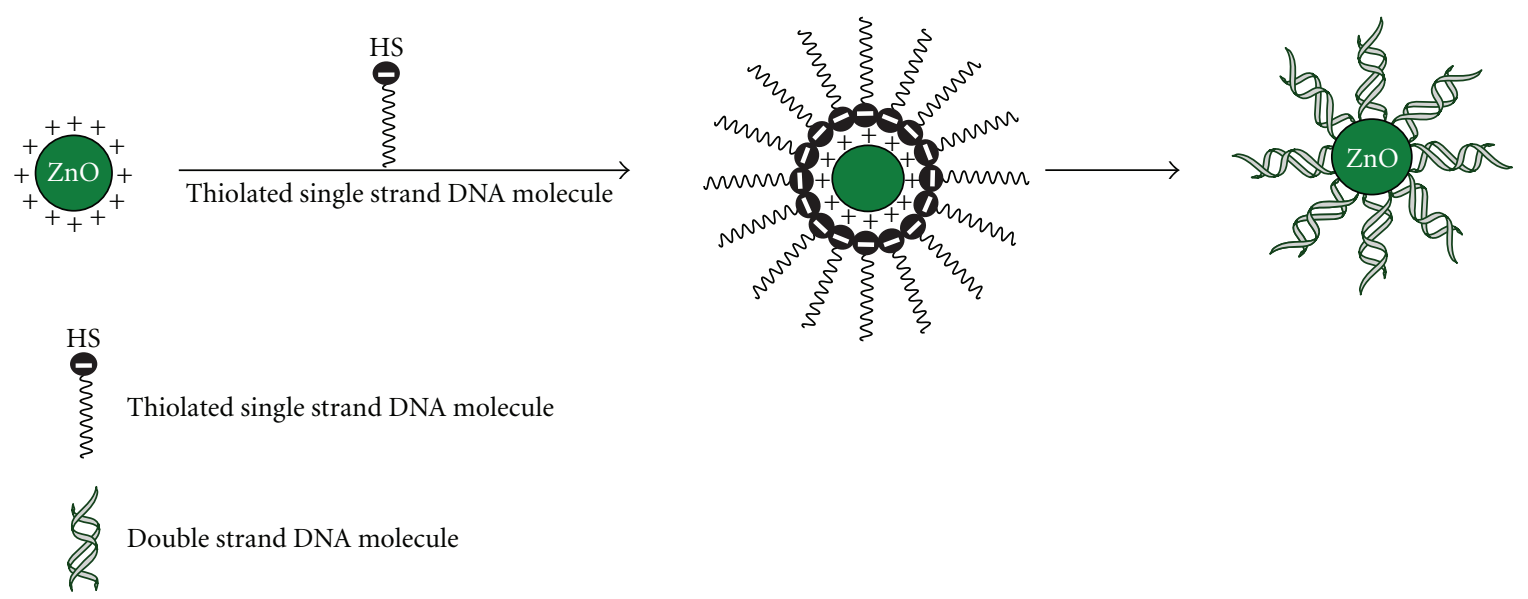

FIGURE 2: Schematic presentation of immobilization of thiolated single-stranded probe DNA on the surface of ZnO for hybridization detection in double-stranded DNA (target DNA).

nucleotide long single stranded DNA molecules through $\mathrm{Au}$ thiol reaction. Then, 37 nucleotide long single stranded DNA template molecules were added to the solution containing the gold nanoparticles functionalized with single stranded DNA. The authors showed that the nanocrystals could be assembled into dimers (parallel and antiparallel) and trimers upon hybridization of the DNA molecule with that of the template molecule. The gold particles could thus be placed at defined positions from each other as schematically shown (Figure 3). Maeda et al. [58] on the other hand, made use of the Au-thiol reaction and the DNA hybridization technique to build a two dimensional DNA network template in which $\mathrm{Au}$ particles are inserted. Moreover, Kuo et al. [66] demonstrate a change in color from red to blue upon assembling of DNA modified gold nanoparticles into regular arrays. This phenomenon indicates the potential of DNAs modified gold nanoparticles to be applied in biosensing or as DNA probes for diagnosis. Furthermore, Reiss et al. [67] described DNA directed assembly of anisotropic nanoparticles on lithographically defined surfaces and in solution. The goal of their research was to assemble anisotropic nanoparticles into functional electronic devices, including memory devices, logic gates, and so forth. DNA was chosen as a "smart glue" to make the particles self assemble into desirable geometries because of its selectivity which results from the specificity an oligonucleotide has for its complementary oligonucleotide.

Steinbrück et al. fairly recently [68] managed to build gold-silver and silver-silver nanoparticle constructs based on DNA hybridization of thiol and amino functionalized oligonucleotides. Their results help to extend the methodic base for biomolecular approaches for the realization of novel nanophotonic and plasmonic elements.

\section{Construction of Semiconductor Nanocrystal Arrays Using DNA}

Semiconductor nanocrystals, renamed quantum dots, refer to the quantum confinement of electrons and hole carriers at dimensions smaller than the Bohr radius. Quantum dot nanocrystals are generally composed of atoms from groups II and VI (that is CdSe, CdS, and CdTe) or III and V (such as InP) at their core. A shell such as $\mathrm{ZnS}$ or $\mathrm{CdS}$ can be further introduced to prevent the surface quenching of excitons in the emissive core and hence the photostability and quantum yield emission.

Several studies on conjugates of semiconductor nanocrystals, with biomolecules have already been published [6972]. These nanometer sized conjugates are biocompatible and provide some advantages over lanthanide probes and organic dyes. In particular, the emission wavelength of quantum dot nanocrystals can be continuously tuned by changing the particle size, and a single light source can be used for simultaneous excitation of all different sized dots. The novel optical properties render quantum dots ideal fluorophores for multicolor and ultrasensitive applications in nanobiotechnology and nanobioengineering.

Many strategies have been used to synthesize semiconductor nanocrystals and their arrays. Torimoto et al. managed to assemble CdS nanoparticles using DNA as a template [73] by making use of the electrostatic interaction between the cationic surface modifiers on the CdS nanocrystals and the phosphate groups in DNA double strands. Cassell et al. [74], on the other hand, adopted a different approach by using DNA to assemble DNA fullerene hybrid organic materials. In their methodology, the negative phosphate backbone of DNA was used as a template to bind and organize C 60 fullerene molecules modified with $\mathrm{N}, \mathrm{N}$-dimethylpyrrolidinium iodide moiety into defined mesoscopic architectures. The modified fullerene is electrostatically complexed to the DNA backbone through cation exchange with sodium in dimethyl sulfoxide (DMSO). More recently, Dittmer and Simmel [75] have grown p-type semiconductor CuS selectively and densely on DNA both in solution and stretched on a surface. Atomic force microscopy and transmission electron microscopy (TEM) measurements displayed chains of $\mathrm{CuS}$ nanoparticles up to $10 \mathrm{~nm}$ diameter separated by less than $40 \mathrm{~nm}$. 


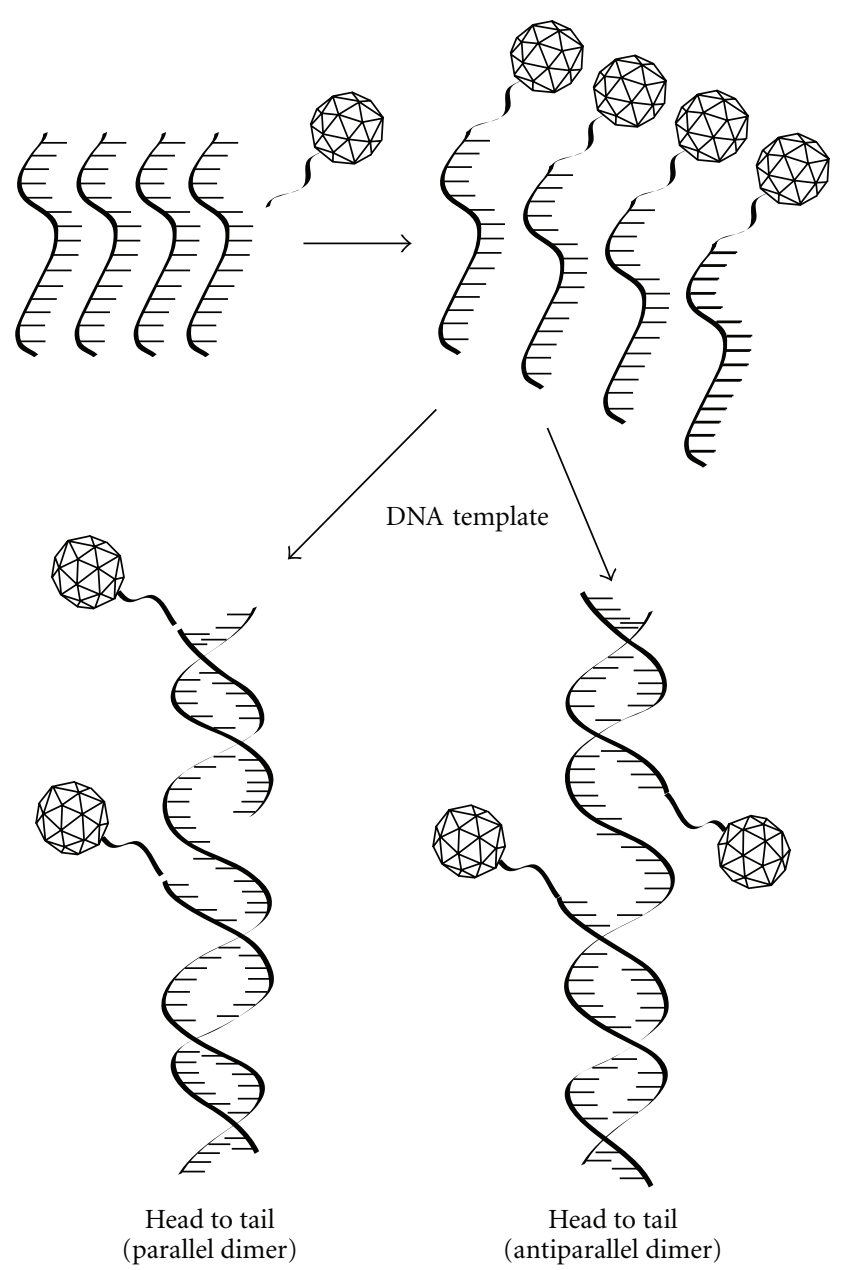

Figure 3: Organization of gold nanocrystals into spatially defined structures.

\section{DNA-Directed Assembly of Nanowires}

The concept of DNA mediated self assembly has been extended to metallic nanowires [76]. An example of the self assembly and subsequent mineralization of DNA in an electronic structure was demonstrated by Braun et al. [76] They hybridized DNA with complementary oligonucleotides attached to gold electrodes to create a single bridge spanning a gap of $12-16 \mu \mathrm{m}$ (Figure 4). The DNA was then used as a template for the directed synthesis of chains of silver nanoclusters from silver ions to produce a conducting nanowire. The corresponding current voltage measurement indicates ohmic behavior with the conductivities close to the bulk metal. It is envisaged that with the correct selection of oligonucleotides, multiple DNA-DNA junctions contacted to an array of electrodes can be used to template standard semiconductor junctions such as bipolar junction transistors and logic junctions. Towards the construction of DNA templated nanowires for self assembled nanodevices, nanocrystals of the p-type semiconductor CuS were grown selectively and densely on DNA both in solution and stretched on a surface [75].

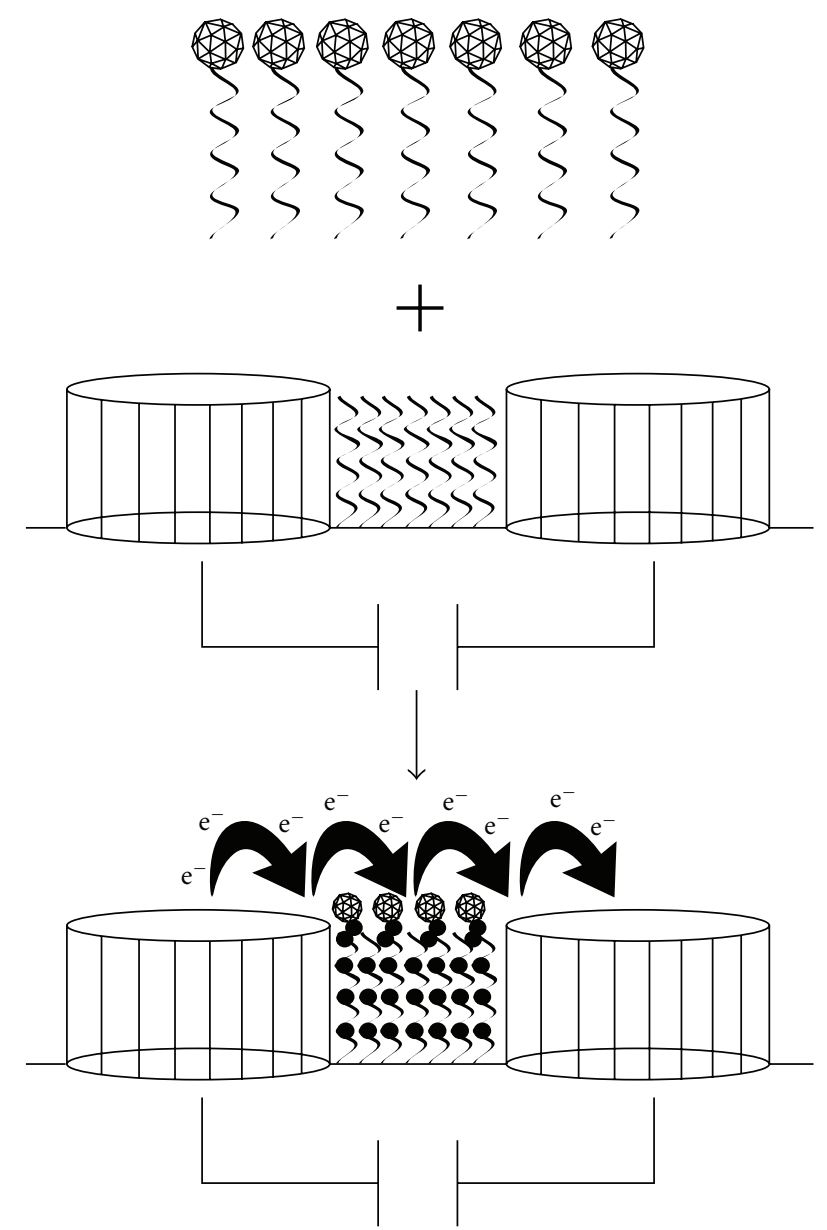

FIGURE 4: Schematic illustration of detecting DNA hybridization signal by integrating the electrical conductivity of nanoparticles using an electrical detection system.

To clearly identify the conduction behavior of DNA molecules Hwang et al. [59] presented a novel method to measure the transport by 60 base pairs of thiol-terminated poly $(\mathrm{dG})-\operatorname{poly}(\mathrm{dC})$ DNA molecules which were chemically anchored to the surface of Au nanoparticles. The DNAattached $\mathrm{Au}$ nanoparticle was self-trapped by the opposite thiol termination in between Au nanoelectrodes to make an electrical conduction channel of electrode-DNA moleculenanoparticle-DNA molecule-DNA molecule-electrode configuration. Two voltage-DNA dependent gaps (1.0 and $1.3 \mathrm{v}$ ) were observed from this system and were considered as the minimum energy required to transfer electrons between DNA bases [77].

Nanowires have been utilized as sensors. They operate on the basis that the change in chemical potential accompanying a target/analyte binding event, such as DNA hybridization [78], can act as field effect gate upon the nanowire, thereby changing its conductance. This is similar in principle, to how a field effect transistor operates.

The ideal nanowire sensor is a single crystal nanowire with a diameter between $10 \mathrm{~nm}$ and $20 \mathrm{~nm}$. It is a formidable task to produce such small width and high aspect ratio 
semiconductors even with electron beam lithography [79]. Nevertheless, other techniques such as superlattice nanowire pattern transfer [80] have demonstrated as being capable of producing large arrays of silicon nanowires with high conductivity characteristics [81].

One prominent advantage of nanowire sensors is that the number and density of the sensor elements is limited only by the ability to electronically address individual nanowires. Thus, large scale circuits can be constructed within very small environment, thereby enabling measurements of large numbers of different proteins and genes from very small tissue samples, or even single cells [82]. For example, Hahm and Lieber [83] grew silicon nanowires $20 \mathrm{~nm}$ wide using vapor deposition onto catalytic nanoparticles. The molecular recognition elements on the nanowire surface consist of peptide nucleic acid (PNA) groups bound by biotin linkers to avidin proteins attached to the wire. Some of the experimented PNA probes contained the full sequence of the gene for the cystic fibrosis transmembrane receptor protein and so were able to bind wild type DNA sequences leading to an abrupt (around $10 \mathrm{~S}$ ), roughly two fold increase in conductance. The authors reason that this is consistent with the binding of negatively charged DNA, and thus an increase in negative surface charge density, at the surface of $\mathrm{p}$ type (hole conducting) semiconducting nanowire. However, exposure of the device to mutant F508 DNA also leads to a similar change in conductance owing to nonspecific binding of the DNA. Nevertheless, mutant DNA can be easily removed from nanowire surface by washing with DNA free solution, reversing the conductance change while wild type DNA becomes securely bound to the PNA receptors and cannot be removed.

\section{DNA-Functionalized Nanotubes}

Carbon nanotubes (CNT) have become the focus of intensive research by analytical chemists for use as electrodes to transmit electrical signals or as sensors to detect concentrations of chemicals or biological material [11, 84-95]. They possess fascinating physical and chemical properties such as electrical conductance, high mechanical stiffness, light weight, electron-spin resonance, field emission, electrochemical actuation, transistor behavior and show the most extreme diversity and richness among nanomaterials referred to structure and associated properties. Since their discovering, CNT have been the goal of numerous investigations due to their unique structural, electronic and mechanical properties that make them a very attractive material for construction of sensitive bio-electronic nanodevices [86105]. Carbon nanotubes are built from $\mathrm{sp}^{2}$ carbon units and present a seamless structure with hexagonal honeycomb lattices, being several nanometers in diameter and many microns in length. CNTs are closed structures that present two well defined regions with clearly different properties, the tube and cap, which is half-fullerene-like pentagonal molecular structure [84-95]. Basically, there are two groups of carbon nanotubes, multiwall (MWCNTs) and singlewall (SWCNTs) carbon nanotubes [92-109]. MWCNTs, can be visualized as concentric and closed graphite tubules with multiple layers of graphite sheets that define a hole typically from 2 to $25 \mathrm{~nm}$ separated by a distance of approximately $0.34 \mathrm{~nm}$. SWCNTs are composed of a single layer of graphene sheet rolled up into a cylinder with diameters in the range 1-2 $\mathrm{nm}$ [88-93]. Single-walled-nanotubes have demonstrated great potential in a variety of nanotechnology applications including molecular electronics [82], hydrogen storage media [92], and scanning probe microscope tips. Due to limited solubility of SWCNTs in common solvents, it is necessary to introduce some functional groups onto their surfaces. Meanwhile, it would endow CNTs with multifunctional applications by integrating other functional groups or materials onto their surface. A functionalized nanotube might have better mechanical, optical or electrical properties as compared to those of the original one [87106]. Therefore, it is an interesting area to functionalize CNTs for all kinds of applications. The functional groups of some organic molecules can form covalent or irreversible van der Waal's bonds with the nanotube, which could alter the $\mathrm{sp}^{2}$ hybridization of CNTs to $\mathrm{sp}^{3}$ type, as a result of functionalization. In 2002, Dwyer et al. firstly reported DNA functionalized CNTs and their effectively dispersion in water by sonication [107]. They found that short oligonucleotides having repeating sequences of guanines and thymines $(\mathrm{dGdT})_{n}(n=10-45)$, could wrap in a helical manner around a CNT with periodic pitch. This finding links one of the central molecules in biology to a technologically very important nanomaterial, and opens the door to CNTs-based applications in biotechnology.

The functionalization of CNTs with DNA molecules increase the CNT solubility in organic media and further application and advancement in DNA based nanobiotechnology. The functionalization character of CNTs with DNA molecules can also be used to distinguish metallic CNT from semiconducting CNTs. DNA chains have various functional structural groups available for covalent interaction with CNTs for construction of DNA-based devices through the sequence-specific pairing interactions. Wang and Lin discussed different modes of DNA for attachment to CNTs [87]. The most ideal approach for DNA immobilization in CNTs is covalent binding on a solid surface via a single point attachment. Most of the applications of immobilized oligonucleotides are based on the hybridization between the immobilized oligonucleotide and its complementary DNA sequence in the sample [87]. The concept of using DNA to direct the assembly of nanotubes into nanoscale devices is attracting attention because of its potential to assemble a multicomponent system in one step by using different, base sequence for each component. The reactive sites on the CNTs were created by the acid treatment to introduce the carboxyl groups on their tips. DNA molecules with functional linkers are then coupled to the carboxyl groups on the CNTs. Chen et al. [110] developed a multistep method to covalently functionalization of multiwall carbon nanotubes with DNA and oligonucleotides. Thus, the bioconjugates of carbon nanomaterials and DNA will have potential uses in many areas due to the combination of unusual structure of carbon nanomaterials and bioactivity of DNA 
[11]. Hazani et al. [111] reported the confocal fluorescence imaging of SWCNT-DNA adducts obtained by carbodiimide assisted coupling of amine functionalized oligonucleotides to oxidized SWCNTs. Modified carbon and other types of nanotubes can be expected to provide a basis for a future generation of nanoscale devices because of their one dimensional electronic band structure, molecular size biocompatibility, and controllable property of conducting electrical current and reversible response to biochemical reagents [92-99]. Consequently, other potential applications include gene therapy, drug delivery and membrane separation [95-106]. DNA has been the research focus [98106] since it can absorb non-covalently as a single strand or double strand complex onto the surface of SWNTS. For example, DNA guided assembly of carbon nanotubes was reported by Dwyer et al. [107], who used amine terminated DNA strands to functionalize the open ends and defect sites of single-walled carbon tubes. Moreover, carbon nanotubes were found to be able to condense double stranded plasmid DNA to varying degrees which paves the way towards the construction of nanotube based gene delivery vectors [106]. The toxicity of carbon nanotube DNA hybrids however should be investigated in a fashion similar to that of pure carbon nanotubes $[108,109]$. In a recent report, a piece of double stranded DNA wrapped on the surface of a singlewalled carbon nanotube was used to detect optically DNA conformational polymorphism [103]. The core of the new optical detection system was based on the transition of DNA secondary structure from the native, right handed " $\mathrm{B}$ " form to the alternate, left handed " $Z$ " form which was modulated by metal ions. In line with this work, Li et al. [88] reported for the first time that DNA destabilization and conformational transition induced by SWNTS are sequence dependent. It is noteworthy hinting that all types of carbon nanotube DNA hybrids mentioned above have different electrostatic properties that depend on the diameter of the nanotube and electronic properties. These differences in properties allow the separation and sorting of nanotubes with anion exchange chromatography $[105,106]$.

\section{DNA-Based Biosensors}

In recent years, there has been tremendous interest in using novel solid state nanomaterials for medical and biological applications. The unique physical properties of nanoscale solids (dots or wires) in conjunction with the remarkable recognition capabilities of biomolecules could lead to miniature biological electronics and optical devices including biosensors and probes. We describe below some interesting examples that utilize nanostructured materials conjugated with DNA as novel biosensors.

Sequence specific DNA detection is an important topic because of its application in the diagnosis of pathogenic and genetic diseases. Many detection techniques have been developed that rely upon target hybridization with fluorescent, chemiluminescent, radioactive, or other types of labeled probes. In addition, there are indirect detection methods that rely on enzymes to generate fluorescent, chemiluminescent

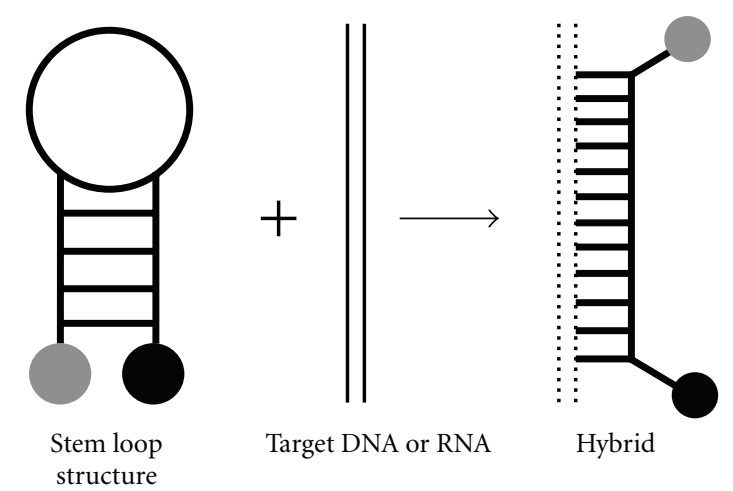

Figure 5: Oligonucleotide molecules designed to form a stem loop structure with a fluorophore linked to the $5^{\prime}$ end and a quencher to the $3^{\prime}$ end [113].

or colorimetric signals. Maxwell et al. [112] developed a novel method for detecting specific DNA sequences and single base mutations. The principle of their detection method relies on oligonucleotide molecules labeled with a thiol group which are attached at one end of the core of a $2.5 \mathrm{~nm}$ gold nanoparticle and a fluorophore at the other end. This hybrid construct is found to spontaneously assemble into a constrained arch like conformation on the particle surface. In the assembled state, the fluorophore is quenched by the nanoparticle. Upon target binding, the conformation opens and the fluorophore leaves the surface because of the structural rigidity of the hybridized double stranded DNA, and fluorescence is restored. This structural change generates a fluorescence signal that is highly sensitive and specific to the target DNA. Another recent fluorescent DNA probe, the molecular beacon (MB) offers unique advantages for ultrasensitive gene analysis [113]. MBs are oligonucleotide molecules designed to form a stem loop structure with a fluorophore linked to the $5^{\prime}$ end and a quencher to $3^{\prime}$ end. No fluorescence is observed due to the close proximity of the fluorophore and the quencher. Upon hybridization of the target oligonucleotide with the $\mathrm{MB}$, the fluorophore and quencher are spatially separated, causing the fluorescence signal to be restored (Figure 5). Su et al. [114] on the other hand, reported a micro cantilever based mechanical resonance DNA detection using gold nanoparticle modified probes. In this technique, captured DNA strands are linked on a cantilever by gold thiol covalent bonding after which the cantilever is dipped into the target DNA solution for hybridization. Next, gold nanoparticles labeled DNA strands are hybridized on the other end of target DNA through complementary interactions. Gold nanoparticles then act as nucleating agent for the growth of silver when exposed to photographic developing solution. The growth of silver particles leads to a detectable frequency shift by increasing the effective mass of the microcantilever, which can be readily detected.

A major challenge in the area of DNA detection is the development of methods that do not rely on polymerase chain reaction or other target amplification systems that 
require additional instrumentation and reagents. For example, nanowires have been utilized as biosensors, to differentiate between wild type and mutant genes, without being amplified, for cystic fibrosis transmembrane receptor protein as described under the section of "DNA-directed assembly of nanowires" above. Another example which makes use of conductivity changes in DNA detection, without target amplification, is that advanced by Park et al. [115]. They detected with their method target DNA at concentration as low as 500 femtomolar with a point mutation selectivity factor of $1: 100000$.

He et al. [116] described a new approach for ultrasensitive detection of DNA hybridization based on nanoparticle amplified surface plasmon resonance. Use of the $\mathrm{Au}$ nanoparticle tags leads to a more than 10 fold increase in angle shift, which corresponds to a more than 100 fold improvement in sensitivity for the target oligonucleotide as compared to the unamplified binding event.

In addition, the oligonucleotide linked semiconductor nanocrsytals (quantum dots) which have been used in DNA hybridization experiments demonstrated that they could very soon become useful biosensors in molecular biology for various applications, such as mapping genes, monitoring their expression and detecting mutations. The specific interaction between complementary nucleic acid strands could indeed be detected either by the formation of nanocrystal aggregates $[117,118]$ or via the sorting of differently colored nanocrystals on supports bearing the matching oligonucleotides [119].

Conjugates of self assembled DNA-streptavidin have also been used as nanobiosensors. For example, the conjugates are used as model systems for ion switchable nanoparticle networks, as nanometer scale "soft material" calibration standards for scanning probe microscopy $[120,121]$, or as programmed building blocks for the rational construction of complex biomolecular architecture, which may be used as templates for the growth of nanometer scale inorganic devices [51, 122]. Moreover, covalent conjugates of single stranded DNA and streptavidin are used as biomolecular means for the immobilization of biotinylated macromolecules at solid substrates through DNA hybridization. This DNA directed immobilization allows for site selective functionalization of substrates with semiconductors and metal for the DNA directed functionalization of gold nanoparticles with immunoglobulins, enzymes and other types of proteins. DNA directed functionalization of biometallic nanostuctures from gold nanoparticles and antibodies are applied as diagnostic tools in bio-analytics $[123,124]$.

Tam et al. [125] have studied a covalently immobilized probe DNA on MWCNTs for direct and label-free detection of influenza virus (type A). The investigators used FTIR and Raman spectra for the confirmation of covalent bonding in between amine and phosphate groups of the DNA sequence. The fabricated DNA biosensor can detect target DNA down to $0.5 \mathrm{nM}$.

Zhu et al. [126] presented a very attractive work about non-covalent functionalization of MWCNTs sidewalls for immobilization of poly(amidoamine) dendrimer to be used for the fabrication of efficient electronic transducers to form the DNA biosensors. The sensitivity and selectivity of the impedimetric biosensor for the target DNA increased to attain a detection limit down to $0.1 \mathrm{pM}$.

In another application, carboxyl group functionalized MWCNTs modified on electropolymerized aminobenzoic acid, covering the surface of the glass-carbon electrode (GCE), were applied for fabrication of sensitive electrochemical DNA biosensors for the detection of target DNA hybridization [127]. For covalent immobilization of DNA molecules $\mathrm{Au}$ nanoparticles layer was introduced onto the nanocomposite electrode surface. Gold nanoparticles promote the electron transfer rate between the redox active DNA species and the electrode surface. Under optimized conditions, DNA hybridization current was monitored by a DPV technique. The biosensor had linearity in a wide concentration range of the complementary ODNs from $1.0 \times$ $10^{-12}$ to $5.0 \times 10^{-9} \mathrm{M}$ with a detection limit of $3.5 \times 10^{-13} \mathrm{M}$ [127].

\section{DNA-Based Gene Delivery}

Efficient DNA delivery is vital for gene therapy, DNA vaccination and the advancement of other clinical therapies. A number of strategies for gene therapy have been proposed including the use of different types of nanovehicles whose unifying feature is the nanometer scale size range (from a few to $250 \mathrm{~nm}$ ). These nanovehicles include viral vectors [128], liposomes [129, 130] and synthetic gene delivery systems [131-133], such as cationic polymeric nanoparticles [134-139], dendrimers [140], and modified inorganic nanoparticles $[141,142]$. Due to the growing concerns over the cytotoxicity and immunogenecity of viral DNA delivery systems, DNA delivery via non-viral routes [143-152] has become more desirable and advantageous because of its low toxicity, little immunogenicity and high adaptability. The ideal non-viral DNA delivery nanosystem should be a synthetic system that mimics viral vectors. It should also be efficient, biocompatible and modular so that it is tunable to various applications in both clinical settings and research. The first synthetic DNA delivery nanosystem which meets most of the above criteria has been reported by Luo and Saltzman [140]. The investigators demonstrated a three component transfection system mediated by silica particles. This three component nanosystem (silica nanoparticles, SuperFect dendrimers, and DNA) is self assembled and effective. It enhanced transfection with most transfection reagents used including cationic lipid based and dendrimer based reagents. Luo et al. [153] on the other hand, used dense silica nanoparticles to concentrate DNA vector (i.e., DNA-transfection reagent) complexes at the surface of cell monolayers which resulted eventually in increased complex concentration at the cell surface. This technique enhanced transfection efficiency by up to 8.5 fold over the best commercially available transfection reagents. Besides, He et al. [154] reported a novel protective DNA nanoenricher for gene delivery based on amino modified silica coated magnetic nanoparticles. Plasmid DNA was made to combine on to the 
positively charged nanoparticle surface to form nanoparticle plasmid DNA complexes. These complexes were found to successfully cross various systemic barriers to COS-7 as well as mediate high expression of Green Fluorescence Protein (GFP) gene in cells. Moreover, magnetofection gave interesting preliminary results in rats and pigs [155] and in particular the feasibility of magnetic guided and site directed gene therapy with antisense oligonucleotides has been positively assessed [156].

\section{Ecological Advantages and Risks of Nanotechnology}

The most pressing near term issues related to nanotechnology in general are toxicity and exposure to humans and the environment. This is a safety and health issue rather than an ethical or a political one.

As technology develops and society evolves, regulatory approaches to environmental, legislative, cultural, and ethical issues must keep pace. Predictions of both opportunities and dangers fail to match reality as the development of nanotechnologies is only in its infant stage. Nevertheless, all indicators of adverse side effects of nanosystems should be carefully considered, even if this process slows down the pace of technological innovation. Moreover, while gaps between science and ethics may occur, they can be bridged through the promotion of multidisciplinary decision making processes that include humanistic and ethical guidance of nanodesign.

The potential advantages of nanobiotechnology include:

(1) The feasibility of producing materials and equipments without producing wasteful and dangerous byproducts.

(2) The possibility of producing devices capable of detecting, measuring and treating different types of pollutants.

On the other hand, in their application to environmental research some nanoparticles may exhibit potential threats to human health owing to their cytotoxicity. There are still many unanswered questions about the fate of nanoparticles introduced into the living body. Because of the huge diversity of nanomaterials used and the wide range of size in particles, their effects are expected to vary considerably. For example, a high throughput gene expression test determined that specially quoted quantum dots fluorescent nanoprobes affect only $2 \%$ of the human genome [157]. These health related effects should be carefully addressed before the contamination of the environment by nanoparticles accumulates.

\section{Conclusion}

The study of DNA-based nanostructure is an attractive field due to its unique structural, physicochemical properties, and recognition capabilities. This review describes the utilization of DNA for preparing nanostructured materials and the use of such nanostructures for various biochemical and medical applications. Various DNA-based nanostructures, including nanostructures by DNA itself, DNA-based assembly of metal and semiconductor nanoparticles, DNA functionalized nanowires, and nanotubes are described. Some interesting and promising examples of using DNA-based nanostructures as biosensors and gene delivery systems are also presented. Further work should, however, concentrate to clarify the mechanism of interaction between nanomaterials and biomolecules, such as DNA, on the surface of multifunctional or homogeneous nanofilms and nanoelectrodes to explore the potential of using novel properties to fabricate a new generation of biosensors. It is anticipated that new useful DNA-based nanostructures will continue to emerge over the next few years. Their investigation at different nanolevels will not only provide valuable fundamental information about their collective biochemical, electrical, magnetic and electrochemical properties but will also provide access to new and useful applications in the industry of biosensors, food analysis, process control, environmental monitoring, diagnostics and treatment of disease.

\section{Acknowledgments}

This work was supported partially by the Center of Excellence in Biotechnology (Project No. CEBR 02) and partially by King Abdulla Institute for Nanotechnology (Res. Project No. Nano 6/1429), King Saud University. The authors would like to thank Faisal Abdul-Aziz Al-Barakat and Ahamad Imran for typing the manuscript.

\section{References}

[1] G. M. Whitesides, "The once and future nanomachine," Scientific American, vol. 285, no. 3, pp. 78-83, 2001.

[2] M. C. Roco and W. S. Bainbridge, Eds., "Converging technologies for improving human performance," NSF Doc Report, 2002.

[3] K. M. Abu Salah and J. B. C. Findlay, "Labelling of egg phosphatidylcholine vesicles and myelin membrane with a photoreative lipophilic reagent," Biochemical Journal, vol. 161, no. 2, pp. 223-228, 1977.

[4] K. M. Abu-Salah, "Alteration of the permeability of the human erythrocyte membrane to cations by liposomeincorporated amphotericin B," European Journal of Clinical Chemistry and Clinical Biochemistry, vol. 30, no. 11, pp. 737744, 1992.

[5] S. Batzri and E. D. Korn, "Single bilayer liposomes prepared without sonication," Biochimica et Biophysica Acta, vol. 298, no. 4, pp. 1015-1019, 1973.

[6] A. J. Baeumner, R. N. Cohen, V. Miksic, and J. Min, "RNA biosensor for the rapid detection of viable Escherichia coli in drinking water," Biosensors and Bioelectronics, vol. 18, no. 4, pp. 405-413, 2003.

[7] J. Riu, A. Maroto, and F. X. Rius, "Nanosensors in environmental analysis," Talanta, vol. 69, no. 2, pp. 288-301, 2006.

[8] D. M. Eigler and E. K. Schweizer, "Positioning single atoms with a scanning tunnelling microscope," Nature, vol. 344, no. 6266, pp. 524-526, 1990.

[9] New Technologies for a Sustainable World, "Hearings before the subcomm. On science, technology and space comm. On commerce, science and transportation, (testimony of Dr. Eric 
Drexler) (Hereafter New Technologies Hearings). 1992,102d Cong. 21".

[10] M. Wautelet, "Scaling laws in the macro-, micro- and nanoworlds," European Journal of Physics, vol. 22, no. 6, pp. 601-611, 2001.

[11] K. M. Abu-Salah, S. A. Alrokyan, M. N. Khan, and A. A. Ansari, "Nanomaterials as analytical tools for genosensors," Sensors, vol. 10, pp. 963-993, 2010.

[12] R. A. Andrievski and A. M. Glezer, "Size effects in properties of nanomaterials," Scripta Materialia, vol. 44, no. 8-9, pp. 1621-1624, 2001.

[13] C. R. Martin and D. T. Mitchell, "Highly sensitive methods for electroanalytical chemistry based on nanotubule membranes," Analytical Chemistry, vol. 70, p. 322A, 1999.

[14] H. S. Nalwa, Handbook of Nanostructured Materials and Nanotechnology, vol. 4, Academic Press, San Diego, Calif, USA, 1999.

[15] R. Kelsall, I. Hamley, and M. Geoghegan, Nanoscale Science and Technology, John Wiley \& Sons, Chichester, UK, 2005.

[16] W. C. W. Chan and S. Nie, "Quantum dot bioconjugates for ultrasensitive nonisotopic detection," Science, vol. 281, no. 5385, pp. 2016-2018, 1998.

[17] S. Santra, K. Wang, R. Tapec, and W. Tan, "Development of novel dye-doped silica nanoparticles for biomarker application," Journal of Biomedical Optics, vol. 6, no. 2, pp. 160-166, 2001.

[18] R. P. Andres, T. Bein, M. Dorogi et al., "'Coulomb staircase" at room temperature in a self-assembled molecular nanostructure," Science, vol. 272, no. 5266, pp. 1323-1325, 1996.

[19] C. B. Murray, C. R. Kagan, and M. G. Bawendi, "Self organization of CdSe nano crystallites into three-dimensional quantam dot super lattices," Science, vol. 270, pp. 1335-1338, 1995.

[20] C. A. Mirkin, R. L. Letsinger, R. C. Mucic, and J. J. Storhoff, "A DNA-based method for rationally assembling nanoparticles into macroscopic materials," Nature, vol. 382, no. 6592, pp. 607-609, 1996.

[21] W. Shenton, D. Pum, U. B. Sleytr, and S. Mann, "Synthesis of cadmium sulphide superlattices using self-assembled bacterial S-layers," Nature, vol. 389, no. 6651, pp. 585-587, 1997.

[22] M. Li, H. Schnablegger, and S. Mann, "Coupled synthesis and self-assembly of nanoparticles to give structures with controlled organization," Nature, vol. 402, no. 6760, pp. 393395, 1999.

[23] H. A. Clark, R. Kopelman, R. Tjalkens, and M. A. Philbert, "Optical nanosensors for chemical analysis inside single living cells. 2. Sensors for $\mathrm{pH}$ and calcium and the intracellular application of PEBBLE sensors," Analytical Chemistry, vol. 71, no. 21, pp. 4837-4843, 1999.

[24] D. P. O'Neal, L. R. Hirsch, N. J. Halas, J. D. Payne, and J. L. West, "Photo-thermal tumor ablation in mice using near infrared-absorbing nanoparticles," Cancer Letters, vol. 209, no. 2, pp. 171-176, 2004.

[25] V. P. Zharov, E. N. Galitovskaya, C. Johnson, and T. Kelly, "Synergistic enhancement of selective nanophotothermolysis with gold nanoclusters: potential for cancer therapy," Lasers in Surgery and Medicine, vol. 37, no. 3, pp. 219-226, 2005.

[26] J. Wilsdon, "The politics of small things: nanotechnology, risk, and uncertainty," IEEE Technology and Society Magazine, vol. 23, no. 4, pp. 16-21, 2004.

[27] L. Mitas, J. Therrirn, R. Twestern, and M. H. Nayfeh, "Effect of surface reconstruction on the structural prototypes of ultra small ultra bright Si29 nanoparticles," Applied Physics Letters, vol. 78, pp. 1918-1920, 2000.

[28] G. Belomoin, J. Therrien, and M. Nayfeh, "Oxide and hydrogen capped ultrasmall blue luminescent Si nanoparticles," Applied Physics Letters, vol. 77, no. 6, pp. 779-781, 2000.

[29] O. Akcakir, J. Therrien, G. Belomoin et al., "Detection of luminescent single ultrasmall silicon nanoparticles using fluctuation correlation spectroscopy," Applied Physics Letters, vol. 76, no. 14, pp. 1857-1859, 2000.

[30] M. Nayfeh, O. Akcakir, J. Therrien et al., "Highly nonlinear photoluminescence threshold in porous silicon," Applied Physics Letters, vol. 75, no. 26, pp. 4112-4114, 1999.

[31] M. H. Nayfeh, N. Barry, J. Therrien, O. Akcakir, E. Gratton, and G. Belomoin, "Stimulated blue emission in reconstituted films of ultrasmall silicon nanoparticles," Applied Physics Letters, vol. 78, no. 8, pp. 1131-1133, 2001.

[32] M. H. Nayfeh, O. Akcakir, G. Belomoin, N. Barry, J. Therrien, and E. Gratton, "Second harmonic generation in microcrystallite films of ultrasmall Si nanoparticles," Applied Physics Letters, vol. 77, no. 25, pp. 4086-4088, 2000.

[33] S. J. Flint, Principles of Virology, ASM Press, 2007.

[34] D. Voet, J. Voet, and C. W. Pratt, Fundamentals of Biochemistry, John Wiley \& Sons, New York, NY, USA, 2nd edition, 2006.

[35] J. D. Waston, T. A. Baker, S. P. Bell, A. Gann, M. Levine, and R. Losick, Molecular Biology of the Gene, Pearson-Benjamin Cummings, San Francisco, Calif, USA, 6th edition, 2008.

[36] R. Holliday, "Mechanism for gene conversion in fungi," Genetics Research, vol. 5, pp. 282-304, 1964.

[37] N. C. Seeman, "Nucleic acid junctions and lattices," Journal of Theoretical Biology, vol. 99, no. 2, pp. 237-247, 1982.

[38] N. C. Seeman, "DNA nanotechnology: novel DNA constructions," Annual Review of Biophysics and Biomolecular Structure, vol. 27, pp. 225-248, 1998.

[39] J. Chen and N. C. Seeman, "Synthesis from DNA of a molecule with the connectivity of a cube," Nature, vol. 350, no. 6319, pp. 631-633, 1991.

[40] Y. Zhang and N. C. Seeman, "Construction of a DNAtruncated octahedron," Journal of the American Chemical Society, vol. 116, no. 5, pp. 1661-1669, 1994.

[41] E. Winfree, F. Liu, L. A. Wenzler, and N. C. Seeman, "Design and self-assembly of two-dimensional DNA crystals," Nature, vol. 394, no. 6693, pp. 539-544, 1998.

[42] C. Mao, W. Sun, and N. C. Seeman, "Designed twodimensional DNA holliday junction arrays visualized by atomic force microscopy," Journal of the American Chemical Society, vol. 121, no. 23, pp. 5437-5443, 1999.

[43] E. Winfree, "On the computational power of DNA annealing and ligation," in DNA Based Computers, R. Lipton and E. Baum, Eds., pp. 199-221, American Mathematical Society, Providence, RI, USA, 1995.

[44] C. Mao, T. H. LaBean, J. H. Reif, and N. C. Seeman, "Logical computation using algorithmic self-assembly of DNA triplecrossover molecules," Nature, vol. 407, no. 6803, pp. 493-496, 2000.

[45] C. Mao, T. H. Labean, J. H. Relf, and N. Seeman, "Erratum in "logical computation using algorithmic self-assembly of triple-crossover molecules"', Nature, vol. 408, no. 6813, p. 750, 2000.

[46] C. Mao, W. Sun, and N. C. Seeman, "Assembly of Borromean rings from DNA,” Nature, vol. 386, no. 6621, pp. 137-138, 1997.

[47] B. Yurke, A. J. Turberfield, A. P. Mills Jr., F. C. Simmel, and J. L. Neumann, "A DNA-fuelled molecular machine made of DNA,” Nature, vol. 406, no. 6796, pp. 605-608, 2000. 
[48] H. Yan, X. Zhang, Z. Shen, and N. C. Seeman, "A robust DNA mechanical device controlled by hybridization topology," Nature, vol. 415, no. 6867, pp. 62-65, 2002.

[49] N. C. Seeman and A. M. Belcher, "Emulating biology: building nanostructures from the bottom up," Proceedings of the National Academy of Sciences of the United States of America, vol. 99, no. 2, pp. 6451-6455, 2002.

[50] B. H. Robinson and N. C. Seeman, "The design of a biochip: a self-assembling molecular-scale memory device," Protein Engineering, vol. 1, no. 4, pp. 295-300, 1987.

[51] K. Keren, M. Krueger, R. Gilad, G. Ben-Yoseph, U. Sivan, and E. Braun, "Sequence-specific molecular lithography on single DNA molecules," Science, vol. 297, no. 5578, pp. 72-75, 2002.

[52] M. Heilemann, P. Tinnefeld, G. S. Mosteiro, M. G. Parajo, N. F. Van Hulst, and M. Sauer, "Multistep energy transfer in single molecular photonic wires," Journal of the American Chemical Society, vol. 126, no. 21, pp. 6514-6515, 2004.

[53] C. M. Niemeyer, J. Koehler, and C. Wuerdermann, "DNA-directed assembly of bioenzymic complexes from in vivo biotinylated NAD (P) H:FMN oxidoreductase and luciferase," ChemBioChem, vol. 3, pp. 242-245, 2002.

[54] J. Bath and A. J. Turberfield, "DNA nanomachines," Nature Nanotechnology, vol. 2, no. 5, pp. 275-284, 2007.

[55] A. A. Ansari, M. N. Khan, M. Alhoshan, A. S. Aldwayyan, and M. S. Alsalhi, "Nanostructured materials: classification, properties, fabrication, characterization and their applications in biomedical sciences," in Nanoparticles: Properties, Classification, Characterization, and Fabrication, A. E. Kestell and G. T. De Lorey, Eds., Nova Science Publishers, Hauppauge, NY, USA, 2010.

[56] C. A. Mirkin, R. L. Lestinger, R. C. Mycic, and J. J. Storholf, "A DNA-based method for rationally assembling nanoparticles macroscopic material," Nature, vol. 382, pp. 607-609, 1996.

[57] A. Kumar, S. Phadtare, R. Pasricha, P. Guga, K. N. Ganesh, and M. Sastry, "Assembling gold nanoparticles in solution using phosphorothioate DNA as structural interconnects," Current Science, vol. 84, no. 1, pp. 71-74, 2003.

[58] Y. Maeda, H. Tabata, and T. Kawai, "Two-dimensional assembly of gold nanoparticles with a DNA network template," Applied Physics Letters, vol. 79, no. 8, pp. 1181-1183, 2001.

[59] J. S. Hwang, S. W. Hwang, and D. Ahn, "Electrical conduction measurement of thiol modified DNA molecules," Superlattices and Microstructures, vol. 34, no. 3-6, pp. 433438, 2003.

[60] S. Pathak, S.-K. Choi, N. Arnheim, and M. E. Thompson, "Hydroxylated quantum dots as luminescent probes for in situ hybridization," Journal of the American Chemical Society, vol. 123, no. 17, pp. 4103-4104, 2001.

[61] A. P. Alivisatos, K. P. Johnsson, X. Peng et al., "Organization of 'nanocrystal molecules' using DNA," Nature, vol. 382, no. 6592, pp. 609-611, 1996.

[62] C. M. Niemeyer, M. Adler, S. Gao, and L. Chi, "Supramolecular nanocircles consisting of streptavidin and DNA," Angewandte Chemie International Edition, vol. 39, no. 17, pp. 3056-3059, 2000.

[63] C. M. Niemeyer, R. Wacker, and M. Adler, "Haptenfunctionalized DNA-streptavidin nanocircles as supramolecular reagents in a competitive immuno-PCR assay," Angewandte Chemie International Edition, vol. 40, no. 17, pp. 3169-3172, 2001.

[64] A. A. Ansari, R. Singh, G. Sumana, and B. D. Malhotra, "Sol-gel derived nano-structured zinc oxide film for sexually transmitted disease sensor," Analyst, vol. 134, no. 5, pp. 9971002, 2009.
[65] A. A. Ansari, P. R. Solanki, A. Kaushik, and B. D. Malhotra, "Recent advances in nanostructured metal oxides based electrochemical biosensors for clinical diagnostics," in Nanostructured Materials for Electrochemical Biosensors, U. Yopgeshwaran, S. Kumar, and S. Chen, Eds., Nova Science Publishers, Hauppauge, NY, USA, 2009.

[66] W.-H. Kuo, S.-M. Shih, S.-C. Yang, Y.-Y. Yuan, and Y.-J. Lin, "Self-assembly of gold nanoparticles by hybridization of two complementary DNAs," Journal of Medical and Biological Engineering, vol. 22, no. 3, pp. 113-116, 2002.

[67] B. D. Reiss, J. N. K. Mbindyo, B. R. Martin et al., "DNAdirected assembly anisotropic nanoparticles on lithographically defined surfaces and in solution," in Anisotropic Nanoparticles-Synthesis, Characterization and Applications, vol. 635 of Materials Research Society Symposium Proceedings, pp. C621-C626, Boston, Mass, USA, November 2000.

[68] A. Steinbrück, A. Csaki, K. Ritter, M. Leich, J. M. Köhler, and W. Fritzsche, "Gold-silver and silver-silver nanoparticle constructs based on DNA hybridization of thiol- and aminofunctionalized oligonucleotides," Journal of Biophotonics, vol. 1, no. 2, pp. 104-113, 2008.

[69] W. C. W. Chan, D. J. Maxwell, X. Gao, R. E. Bailey, M. Han, and S. Nie, "Luminescent quantum dots for multiplexed biological detection and imaging," Current Opinion in Biotechnology, vol. 13, no. 1, pp. 40-46, 2002.

[70] W. C. W. Chan and S. Nie, "Quantum dot bioconjugates for ultrasensitive nonisotopic detection," Science, vol. 281, no. 5385, pp. 2016-2018, 1998.

[71] R. F. Service, "Semiconductor beacons light up cell structures," Science, vol. 281, no. 5385, pp. 1930-1931, 1998.

[72] D. Gerion, W. J. Parak, S. C. Williams, D. Zanchet, C. M. Micheel, and A. P. Alivisatos, "Sorting fluorescent nanocrystals with DNA," Journal of the American Chemical Society, vol. 124, no. 24, pp. 7070-7074, 2002.

[73] T. Torimoto, M. Yamashita, S. Kuwabata, T. Sakata, H. Mori, and $\mathrm{H}$. Yoneyama, "Fabrication of CdS nanoparticle chains along DNA double strands," Journal of Physical Chemistry B, vol. 103, no. 42, pp. 8799-8803, 1999.

[74] A. M. Cassell, W. A. Scrivens, and J. M. Tour, "Assembly of DNA/fullerene hybrid materials," Angewandte Chemie International Edition, vol. 37, no. 11, pp. 1528-1531, 1998.

[75] W. U. Dittmer and F. C. Simmel, "Chains of semiconductor nanoparticles templated on DNA," Applied Physics Letters, vol. 85, no. 4, pp. 633-635, 2004.

[76] E. Braun, Y. Eichen, U. Sivan, and G. Ben-Yoseph, "DNAtemplated assembly and electrode attachment of a conducting silver wire," Nature, vol. 391, no. 6669, pp. 775-778, 1998.

[77] J. S. Hwang, K. J. Kong, D. Ahn, G. S. Lee, D. J. Ahn, and S. W. Hwang, "Electrical transport through 60 base pairs of poly(dG)-poly(dC) DNA molecules," Applied Physics Letters, vol. 81, no. 6, p. 1134, 2002.

[78] J.-I. Hahm and C. M. Lieber, "Direct ultrasensitive electrical detection of DNA and DNA sequence variations using nanowire nanosensors," Nano Letters, vol. 4, no. 1, pp. 51-54, 2004.

[79] C. Vieu, F. Carcenac, A. Pépin et al., "Electron beam lithography: resolution limits and applications," Applied Surface Science, vol. 164, no. 1-4, pp. 111-117, 2000.

[80] N. A. Melosh, A. Boukai, F. Diana et al., "Ultrahigh-density nanowire lattices and circuits," Science, vol. 300, no. 5616, pp. 112-115, 2003.

[81] R. A. Beckman, E. Johnston-Halperin, N. A. Melosh, Y. Luo, J. E. Green, and J. R. Heath, "Fabrication of conducting Si 
nanowire arrays," Journal of Applied Physics, vol. 96, no. 10, pp. 5921-5923, 2004.

[82] L. Hood, J. R. Heath, M. E. Phelps, and B. Lin, "Systems biology and new technologies enable predictive and preventative medicine," Science, vol. 306, no. 5696, pp. 640-643, 2004.

[83] J.-I. Hahm and C. M. Lieber, "Direct ultrasensitive electrical detection of DNA and DNA sequence variations using nanowire nanosensors," Nano Letters, vol. 4, no. 1, pp. 51-54, 2004.

[84] M. Trojanowicz, "Analytical applications of carbon nanotubes: a review," Trends in Analytical Chemistry, vol. 25, no. 5, pp. 480-489, 2006.

[85] N. Behabtu, M. J. Green, and M. Pasquali, "Carbon nanotube-based neat fibers," Nano Today, vol. 3, no. 5-6, pp. 24-34, 2008.

[86] H. Dai, "Carbon nanotubes: synthesis, integration, and properties," Accounts of Chemical Research, vol. 35, no. 12, pp. 1035-1044, 2002.

[87] J. Wang and Y. Lin, "Functionalized carbon nanotubes and nanofibers for biosensing applications," Trends in Analytical Chemistry, vol. 27, no. 7, pp. 619-626, 2008.

[88] X. Li, Y. Peng, and X. Qu, "Carbon nanotubes selective destabilization of duplex and triplex DNA and inducing BA transition in solution," Nucleic Acids Research, vol. 34, no. 13, pp. 3670-3676, 2006.

[89] K. A. Williams, P. T. M. Veenhuizen, B. G. De la Torre, R. Eritja, and C. Dekker, "Nanotechnology: carbon nanotubes with DNA recognition," Nature, vol. 420, no. 6917, p. 761, 2002.

[90] D. A. Heller, E. S. Jeng, T.-K. Yeung et al., "Optical detection of DNA conformational polymorphism on single-walled carbon nanotubes," Science, vol. 311, no. 5760, pp. 508-511, 2006.

[91] M. S. Dresselhaus, G. Dresselhaus, and P. Avouris, Eds., Carbon Nanotubes: Synthesis, Structure, Properties and Applications, Springler, Berhin, Germany, 2001.

[92] S. Iijima, "Helical microtubules of graphitic carbon," Nature, vol. 354, no. 6348, pp. 56-58, 1991.

[93] J. Liu, A. G. Rinzler, H. Dai et al., "Fullerene pipes," Science, vol. 280, no. 5367, pp. 1253-1256, 1998.

[94] K. Keren, R. S. Berman, E. Buchstab, U. Sivan, and E. Braun, "DNA-templated carbon nanotube field-effect transistor," Science, vol. 302, no. 5649, pp. 1380-1382, 2003.

[95] S. S. Wong, E. Joselevich, A. T. Wooley, C. L. Cheung, and C. M. Lieber, "Covalently functionalized nanotubes as nanometer sized probes in chemistry and biology," Nature, vol. 394, pp. 52-55, 1998.

[96] Y. Lin, S. Taylor, H. Li et al., "Advances toward bioapplications of carbon nanotubes," Journal of Materials Chemistry, vol. 14, no. 4, pp. 527-541, 2004.

[97] N. W. S. Kam, M. O'Connell, J. A. Wisdom, and H. Dai, "Carbon nanotubes as multifunctional biological transporters and near-infrared agents for selective cancer cell destruction," Proceedings of the National Academy of Sciences of the United States of America, vol. 102, no. 33, pp. 11600-11605, 2005.

[98] H. Gao, Y. Kong, D. Cui, and C. S. Ozkan, "Spontaneous insertion of DNA oligonucleotides into carbon nanotubes," Nano Letters, vol. 3, no. 4, pp. 471-473, 2003.

[99] G. I. Dovbeshko, O. P. Repnytska, E. D. Obraztsova, and Y. V. Shtogun, "DNA interaction with single-walled carbon nanotubes: a SEIRA study," Chemical Physics Letters, vol. 372, no. 3-4, pp. 432-437, 2003.

[100] C. Hu, Y. Zhang, G. Bao, Y. Zhang, M. Liu, and Z. L. Wang, "DNA functionalized single-walled carbon nanotubes for electrochemical detection," Journal of Physical Chemistry B, vol. 109, no. 43, pp. 20072-20076, 2005.

[101] M. Zheng, A. Jagota, E. D. Semke et al., "DNA-assisted dispersion and separation of carbon nanotubes," Nature Materials, vol. 2, no. 5, pp. 338-342, 2003.

[102] M. Zheng, A. Jagota, M. S. Strano et al., "Structurebased carbon nanotube sorting by sequence-dependent DNA assembly," Science, vol. 302, no. 5650, pp. 1545-1548, 2003.

[103] J. Rajendra, M. Baxendale, L. G. D. Rap, and A. Rodger, "Flow linear dichroism to probe binding of aromatic molecules and DNA to single-walled carbon nanotubes," Journal of the American Chemical Society, vol. 126, no. 36, pp. 1118211188, 2004.

[104] G. Lu, P. Maragakis, and E. Kaxiras, "Carbon nanotube interaction with DNA," Nano Letters, vol. 5, no. 5, pp. 897900, 2005.

[105] H. Gao and Y. Kong, "Simulation of DNA nanotube interaction," Annual Review of Materials Research, vol. 34, pp. 123150, 2004.

[106] R. Singh, D. Pantarotto, D. McCarthy, et al., "Binding and condensation of plasmid DNA onto functionalized carbon nanotubes: toward the construction of nanotube based gene delivery vectors," Journal of the American Chemical Society, vol. 127, pp. 4388-4396, 2005.

[107] C. Dwyer, M. Guthold, M. Falvo, S. Washburn, R. Superfine, and D. Erie, "DNA-functionalized single-walled carbon nanotubes," Nanotechnology, vol. 13, no. 5, pp. 601-604, 2002.

[108] M. Bottini, S. Bruckner, K. Nika et al., "Multi-walled carbon nanotubes induce T lymphocyte apoptosis," Toxicology Letters, vol. 160, no. 2, pp. 121-126, 2006.

[109] D. Cui, F. Tian, C. S. Ozkan, M. Wang, and H. Gao, "Effect of single wall carbon nanotubes on human HEK 293 cells," Toxicology Letters, vol. 155, pp. 73-85, 2005.

[110] W. W. Chen, C. H. Tzang, J. X. Tang, M. S. Yang, and S. T. Lee, "Covalently linked deoxy ribonucleic acid with multiwall carbon nanotubes-synthesis and characterization," Applied Physics Letters, vol. 86, Article ID 103114, 2005.

[111] M. Hazani, R. Naaman, F. Hennrich, and M. M. Kappes, "Confocal fluorescence imaging of DNA-functionalized carbon nanotubes," Nano Letters, vol. 3, no. 2, pp. 153-155, 2003.

[112] D. J. Maxwell, J. R. Taylor, and S. Nie, "Self-assembled nanoparticle probes for recognition and detection of biomolecules," Journal of the American Chemical Society, vol. 124, no. 32, pp. 9606-9612, 2002.

[113] X. Fang, J. J. Li, J. Perlette, W. Tan, and K. Wang, "Molecular beacons: novel fluorescent probes," Analytical Chemistry, vol. 72, no. 23, pp. 747A-753A, 2000.

[114] M. Su, S. Li, and V. P. Dravid, "Microcantilever resonancebased DNA detection with nanoparticle probes," Applied Physics Letters, vol. 82, no. 20, pp. 3562-3564, 2003.

[115] S.-J. Park, T. A. Taton, and C. A. Mirkin, "Array-based electrical detection of DNA with nanoparticle probes," Science, vol. 295, no. 5559, pp. 1503-1506, 2002.

[116] L. He, M. D. Musick, S. R. Nicewarner et al., "Detection of DNA hybridization with Au nanoparticles and plasmon resonance," Journal of the American Chemical Society, vol. 122, p. 907, 2000.

[117] B. Dubertret, P. Skourides, D. J. Norris, V. Noireaux, A. H. Brivanlou, and A. Libchaber, "In vivo imaging of quantum dots encapsulated in phospholipid micelles," Science, vol. 298, no. 5599, pp. 1759-1762, 2002. 
[118] G. P. Mitchell, C. A. Mirkin, and R. L. Letsinger, "Programmed assembly of DNA functionalized quantum dots," Journal of the American Chemical Society, vol. 121, no. 35, pp. 8122-8123, 1999.

[119] E. Klerreich, "Biologists join the dots," Nature, vol. 413, pp. 450-452, 2001.

[120] S. Gao, L. Chi, S. Lenhert et al., "High-quality mapping of DNA-protein complexes by dynamic scanning force microscopy," ChemPhysChem, vol. 2, no. 6, pp. 384-388, 2001.

[121] B. Pignataro, L. F. Chi, S. Gao, et al., "Dynamic scanning force microscopy study of self-assembled DNA-protein oligomers," Applied Physics A, vol. 74, pp. 447-452, 2002.

[122] C. M. Niemeyer, "Nanotechnology: tools for the biomolecular engineer," Science, vol. 297, no. 5578, pp. 62-63, 2002.

[123] C. M. Niemeyer, "Semi-synthetic DNA-protein conjugates: novel tools in analytics and nanobiotechnology," Biochemical Society Transactions, vol. 32, no. 1, pp. 51-53, 2004.

[124] M. T. Castañeda, A. Merkoçi, M. Pumera, and S. Alegret, "Electrochemical genosensors for biomedical applications based on gold nanoparticles," Biosensors and Bioelectronics, vol. 22, no. 9-10, pp. 1961-1967, 2007.

[125] P. D. Tam, N. V. Hieu, N. D. Chein, A. T. Le, and M. A. Tuan, "DNA sensor development based on multi-wall carbon nanotubes for label-free influenza virus (type A) detection," Journal of Immunological Methods, vol. 350, no. 1-2, pp. 118124, 2009.

[126] N. Zhu, H. Gao, Q. Xu, Y. Lin, L. Su, and L. Mao, "Sensitive impedimetric DNA biosensor with poly(amidoamine) dendrimer covalently attached onto carbon nanotube electronic transducers as the tether for surface confinement of probe DNA," Biosensors and Bioelectronics, vol. 25, no. 6, pp. 14981503, 2009.

[127] Y. Zhang, J. Wang, and M. Xu, "A sensitive DNA biosensors fabricated with gold nanoparticles/poly(p-aminobenzoic acid)/carbon nanotubes modified electrode," Colloids and Surfaces B, vol. 75, pp. 179-185, 2009.

[128] P. Blezinger, J. Wang, M. Gondo, et al., "Systemic inhibition of tumor growth and tumor metastases by intramuscular administration of the endostatin gene," Nature Biotechnology, vol. 17, no. 4, pp. 343-348, 2007.

[129] K. Hirao, T. Sugita, T. Kubo, et al., "Targeted gene delivery to human osteosarcoma cells with magnetic cationic liposomes under a magnetic field," International Journal of Oncology, vol. 22, pp. 1065-1071, 2003.

[130] G. Gregoriadis and A. T. Florence, "Liposomes in drug delivery. Clinical, diagnostic and ophthalmic potential," Drugs, vol. 45, no. 1, pp. 15-28, 1993.

[131] P. Couvreur, G. Barratt, E. Fattal, P. Legrand, and C. Vauthier, "Nanocapsule technology: a review," Critical Reviews in Therapeutic Drug Carrier Systems, vol. 19, no. 2, pp. 99-134, 2002.

[132] S. K. Sahoo and V. Labhasetwar, "Nanotech approaches to drug delivery and imaging," Drug Discovery Today, vol. 8, no. 24, pp. 1112-1120, 2003

[133] S. S. Davis, "Biomedical applications of nanotechnologyimplications for drug targeting and gene therapy," Trends in Biotechnology, vol. 15, no. 6, pp. 217-224, 1997.

[134] Y. Zhang, T. Jin, and R.-X. Zhuo, "Methotrexate-loaded biodegradable polymeric micelles: preparation, physicochemical properties and in vitro drug release," Colloids and Surfaces B, vol. 44, no. 2-3, pp. 104-109, 2005.

[135] K. Ulbrich and V. Šubr, "Polymeric anticancer drugs with pH-controlled activation," Advanced Drug Delivery Reviews, vol. 56, no. 7, pp. 1023-1050, 2004.
[136] M. C. Morris, L. Chaloin, F. Heitz, and G. Divita, "Translocating peptides and proteins and their use for gene delivery," Current Opinion in Biotechnology, vol. 11, no. 5, pp. 461-466, 2000.

[137] A. R. Bender, H. Von Briesen, J. Kreuter, I. B. Duncan, and H. Rubsamen-Waigmann, "Efficiency of nanoparticles as a carrier system for antiviral agents in human immunodeficiency virus-infected human monocytes/macrophages in vitro," Antimicrobial Agents and Chemotherapy, vol. 40, no. 6, pp. 1467-1471, 1996.

[138] M. Junghans, J. Kreuter, and A. Zimmer, "Antisense delivery using protamine-oligonucleotide particles," Nucleic Acids Research, vol. 28, no. 10, article E45, 2000.

[139] E. Dauty, J.-S. Remy, T. Blessing, and J.-P. Behr, “Dimerizable cationic detergents with a low $\mathrm{cmc}$ condense plasmid DNA into nanometric particles and transfect cells in culture," Journal of the American Chemical Society, vol. 123, no. 38, pp. 9227-9234, 2001.

[140] D. Luo and W. M. Saltzman, "Enhancement of transfection by physical concentration of DNA at the cell surface," Nature Biotechnology, vol. 18, no. 8, pp. 893-895, 2000.

[141] C. Kneuer, M. Sameti, E. G. Haltner et al., "Silica nanoparticles modified with aminosilanes as carriers for plasmid DNA," International Journal of Pharmaceutics, vol. 196, no. 2, pp. 257-261, 2000.

[142] K. K. Sandhu, C. M. McIntosh, J. M. Simard, S. W. Smith, and V. M. Rotello, "Gold nanoparticle-mediated transfection of mammalian cells," Bioconjugate Chemistry, vol. 13, no. 1, pp. 3-6, 2002.

[143] L. Xu, P. Frederik, K. F. Pirollo et al., "Self-assembly of a virusmimicking nanostructure system for efficient tumor-targeted gene delivery," Human Gene Therapy, vol. 13, no. 3, pp. 469$481,2002$.

[144] R. Forjo, J. Skaggs, A. B. Quiambao, M. J. Cooper, and M. I. Naash, "Non-viral gene delivery for ocular diseases with compacted DNA nanoparticles," Molecular Therapy, vol. 11, pp. 258-263, 2005.

[145] D. M. Yurek, A. Fletcher-Turner, and M. J. Copper, "Compacted DNA nanoparticles effectively transfect brain cells in vitro and in vivo," Molecular Therapy, vol. 11, pp. 253-258, 2005.

[146] A.-G. Ziady, C. R. Gedeon, T. Miller et al., "Transfection of airway epithelium by stable PEGylated poly-L-lysine DNA nanoparticles in vivo," Molecular Therapy, vol. 8, no. 6, pp. 936-947, 2003.

[147] G. Liu, D. Li, M. K. Pasumarthy et al., "Nanoparticles of compacted DNA transfect postmitotic cells," Journal of Biological Chemistry, vol. 278, no. 35, pp. 32578-32586, 2003.

[148] X. Chen and P. B. Davis, "Compacted DNA nanoparticles transfect cells by binding to cell surface nucleolin," Molecular Therapy, vol. 13, pp. 5152-5157, 2006.

[149] H. Malonga, J. F. Neault, S. Diamantoglou, and H. A. TajmirRiahi, "Taxol anticancer activity and DNA binding," MiniReviews in Medicinal Chemistry, vol. 5, no. 3, pp. 307-311, 2005.

[150] H.-Q. Mao, K. Roy, V. L. Troung-Le et al., "Chitosan-DNA nanoparticles as gene carriers: synthesis, characterization and transfection efficiency," Journal of Controlled Release, vol. 70, no. 3, pp. 399-421, 2001.

[151] M. Iqbal, W. Lin, I. Jabbal-Gill, S. S. Davis, M. W. Steward, and L. Illum, "Nasal delivery of chitosan-DNA plasmid expressing epitopes of respiratory syncytial virus (RSV) induces protective CTL responses in BALB/c mice," Vaccine, vol. 21, no. 13-14, pp. 1478-1485, 2003. 
[152] S. Mansouri, P. Lavigne, K. Corsi, M. Benderdour, E. Beaumont, and J. C. Fernandes, "Chitosan-DNA nanoparticles as non-viral vectors in gene therapy: strategies to improve transfection efficacy," European Journal of Pharmaceutics and Biopharmaceutics, vol. 57, no. 1, pp. 1-8, 2004.

[153] D. Luo, E. Han, N. Belcheva, and W. M. Saltzman, "A selfassembled, modular DNA delivery system mediated by silica nanoparticles," Journal of Controlled Release, vol. 95, no. 2, pp. 333-341, 2004.

[154] X. X. He, K. M. Wang, W. H. Tan, X. Lin, L. Chen, and X. H. Chen, "A novel method for efficient gene delivery using amino-modified silica coated magnetic nanoparticles," Reviews on Advanced Materials Science, vol. 5, no. 4, pp. 375380, 2003.

[155] F. Scherer, M. Anton, U. Schillinger et al., "Magnetofection: enhancing and targeting gene delivery by magnetic force in vitro and in vivo," Gene Therapy, vol. 9, no. 2, pp. 102-109, 2002.

[156] F. Krötz, C. de Wit, H.-Y. Sohn et al., "Magnetofection-a highly efficient tool for antisense oligonucleotide delivery in vitro and in vivo," Molecular Therapy, vol. 7, no. 5, pp. 700710,2003

[157] T. Zhang, J. L. Stilwell, D. Gerion et al., "Cellular effect of high doses of silica-coated quantum dot profiled with high throughput gene expression analysis and high content cellomics measurements," Nano Letters, vol. 6, no. 4, pp. 800808, 2006. 

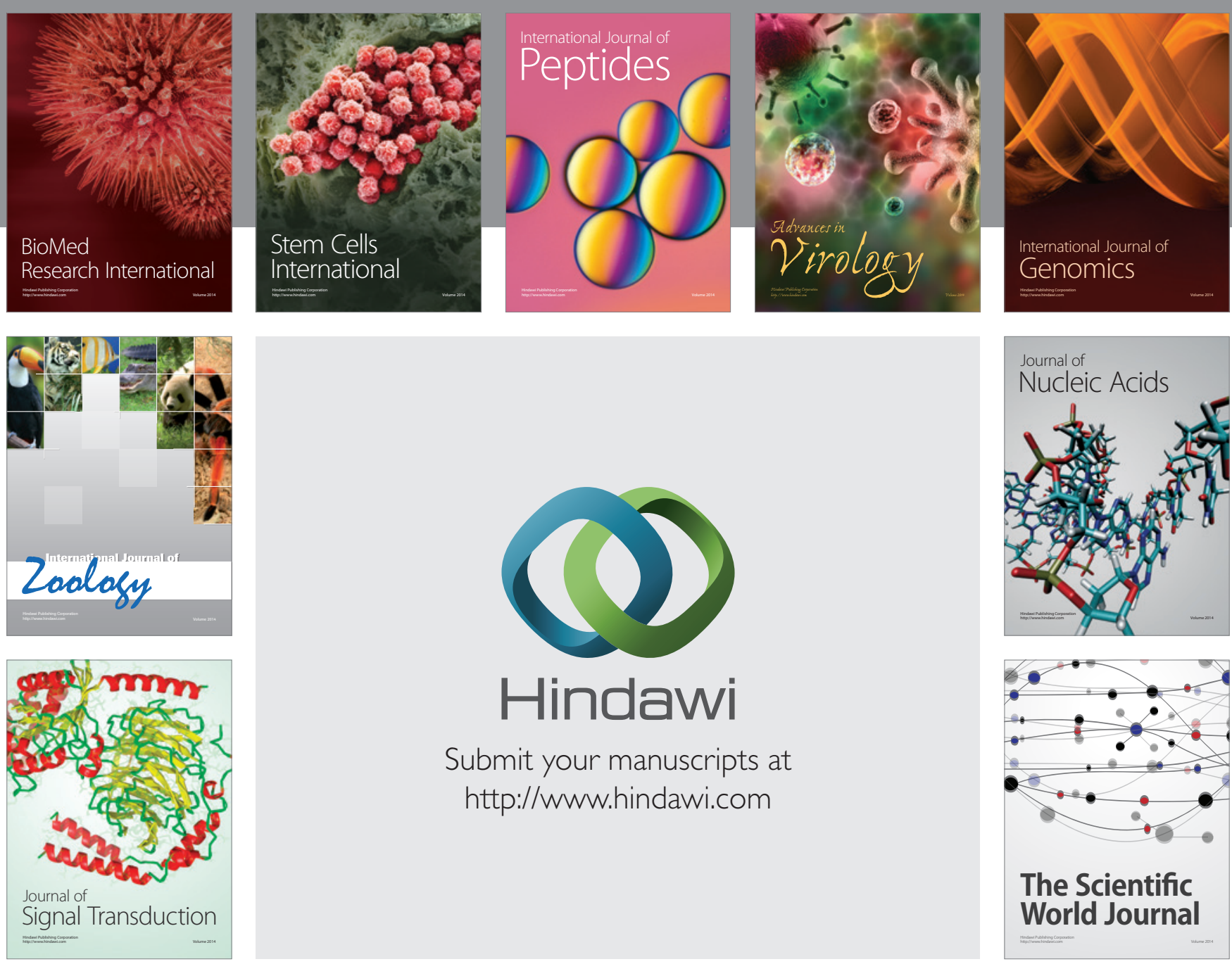

Submit your manuscripts at

http://www.hindawi.com
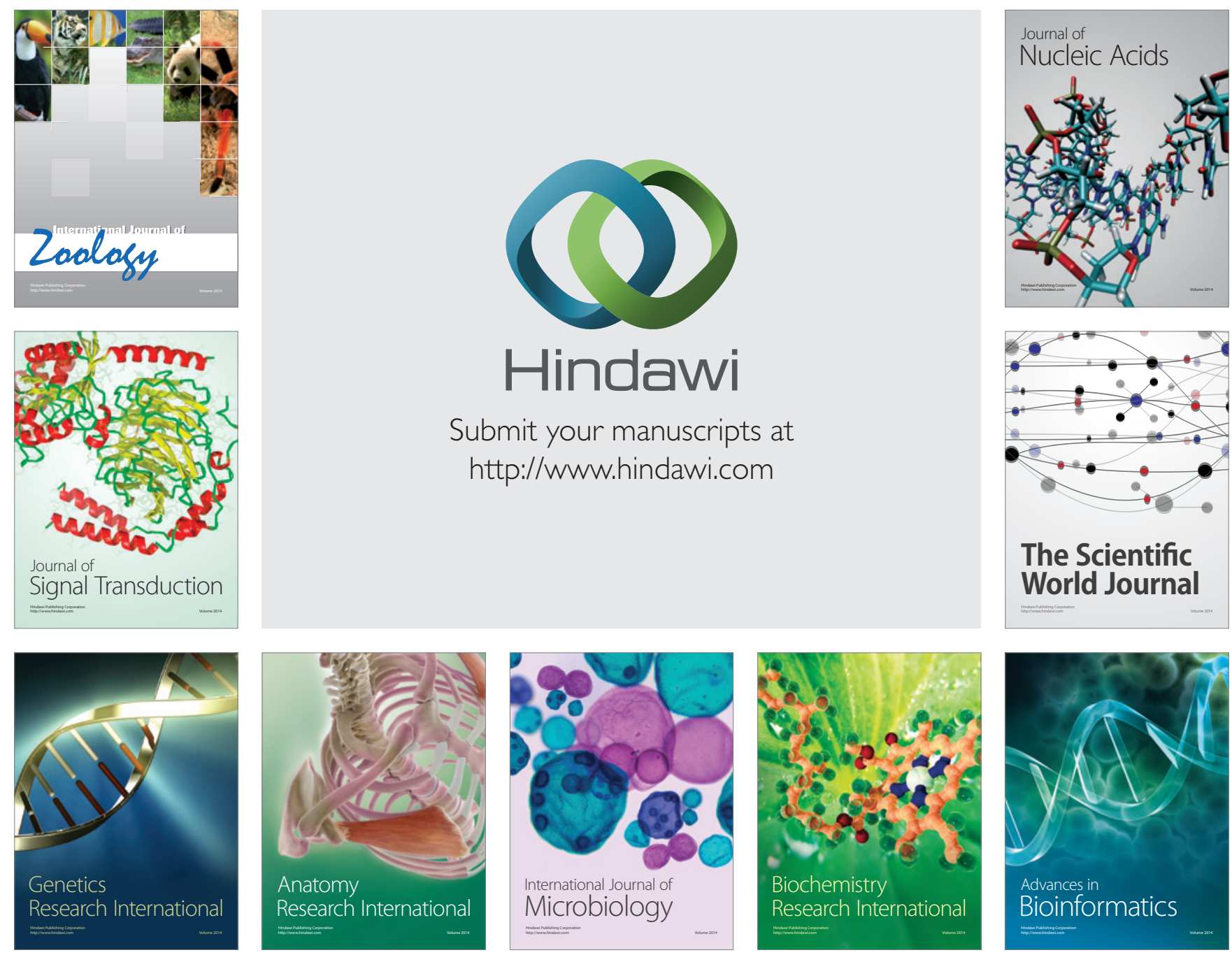

The Scientific World Journal
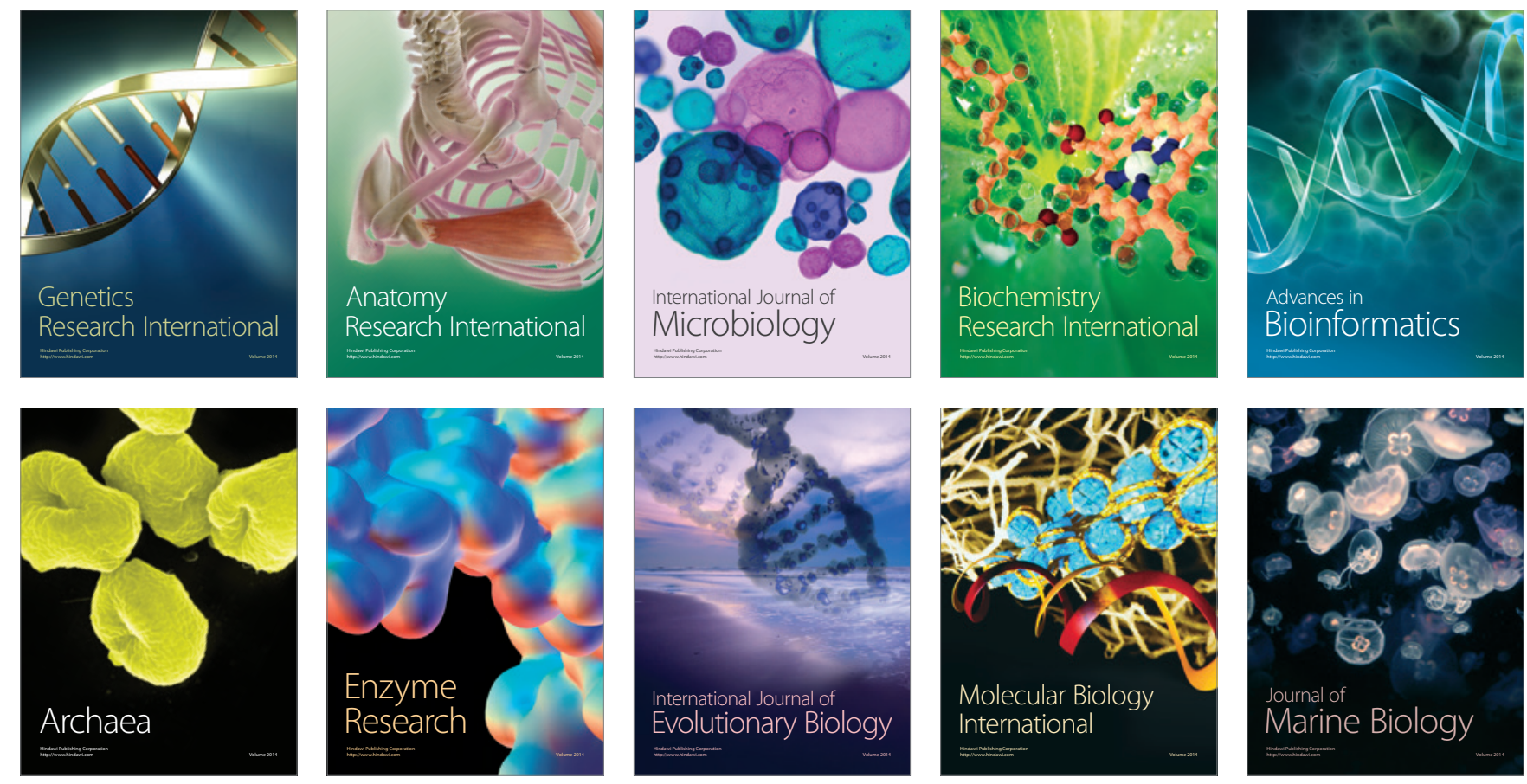